\title{
PROPRIEDADE INTELECTUAL
}

\author{
E \\ DEFESA DA CONCORRÊNCIA
}

\author{
VOLUME 1
}

Rafael Pinho Senra de Morais, PhD. 


\section{Agradecimentos}

Às pessoas que acreditam que Educação e Pesquisa não são Gastos e sim Investimento, e que bolsas de pesquisa produzem conhecimento (científico) e formam cidadãos (mais conscientes).

No presente caso concreto, à então Secretaria de Assuntos Estratégicos da Presidência da República (SAE/PR), ao Programa das Nações Unidas para o Desenvolvimento (PNUD), em particular seu braço executor no Brasil, e à Fundaç

ão Carlos Chagas Filho de Amparo à Pesquisa do Estado do Rio de Janeiro (FAPERJ). Sem o financiamento destas instituições e a dedicação de pessoas - brasileiros como nós, com a crença exposta no parágrafo anterior - as pesquisas que originaram estes livros não teriam ocorrido.

Por fim, aos alunos de graduação - bolsistas ou não - que me auxiliaram e muito na confecção deste material. Letícia Klotz Silva, à época bolsista de pesquisa do Instituto Brasileiro de Pesquisa Econômica (IPEA), em temas correlatos mas não sob minha orientação, foi imprescindível na confecção do material que originou o segundo volume desta série, qual seja o compêndio de jurisprudência nacional e internacional que vai até 2011. Luana Costa de Carvalho e Silva, bolsista de iniciação científica (IC) da Faperj em 2017-2018, sob minha orientação, foi a responsável pelo desenvolvimento da metodologia de captura no sistema SEI do CADE, pelo mapeamento e fichamento dos casos nacionais que compõem o terceiro volume desta série. Augusto Cesar Garcia Tinoco a sucedeu na bolsa, que foi então renovada, sendo portanto bolsista IC da Faperj em 20182019 e o responsável pelo mapeamento e fichamento dos casos internacionais que compõem o terceiro volume desta série.

Gabriel Carvalho de Brito, meu assistente para toda hora e tarefa há ao menos um ano e sem bolsa, foi primordial na fase final de conversão deste material de pesquisa em livros. Jean Carlos de Souza Soares Braga e Felipe da Conceição Nunes, hoje bolsistas de extensão do CNPq sob minha orientação, mas que começaram comigo me ajudando (graciosamente) a difundir conceitos de Economia para o grande público (www.facebook.com/economiaeparatodos) também ajudaram bastante na reta final. Outros novos colaboradores me auxiliaram na revisão final do texto: Breno Novaes, Bruno Cabral, Caio Medeiros e Mariana Sandroni.

Todo o trabalho de todos estes competentíssimos alunos foi orientado e revisado por mim, por suposto, e todos os eventuais erros remanescentes são, obviamente, meus.

$\mathrm{Ah}$ ! E à minha muito amada Dani, esposa dedicada e diagramadora quando possível.

Rio de Janeiro, 15 de dezembro de 2019

Rafael Pinho Senra de Morais

Rafael Pinho de Morais, PhD.

www.rafaelpinhodemorais.com.br 


\section{Apresentações}

Este primeiro volume desta série sobre a interface entre Propriedade Intelectual e Defesa da Concorrência é o volume mais robusto, mais longo e de mais conteúdo. Ele cobre toda a parte teórica da interface, sua evolução histórica e seu entendimento atual.

Boa leitura !!!

\section{Do Autor}

\section{Rafael Pinho Senra de Morais}

www.rafaelpinhodemorais.com.br

http://lattes.cnpq.br/7948891961027768

Rafael é Ph.D. em Economia pela Toulouse School of Economics (2009), Mestre (D.E.A.) em Teoria Econômica e Econometria pela Toulouse School of Economics (2003), Mestre em Economia pela Escola de Pós-Graduação em Economia da Fundação Getulio Vargas (2002), Bacharel em Direito pela Universidade do Estado do Rio de Janeiro (2000) e Economista pelo Instituto Brasileiro de Mercado de Capitais (1999).

Rafael foi Professor Pesquisador da FGV Direito Rio em tempo integral (2008-2010) e depois (2011-2014) lecionou na graduação em Economia da FGV-RJ (em Economia da Regulação e em Defesa da Concorrência) e da PUC-RJ (em Econometria I e em Análise Econômica do Direito). Também lecionou anualmente de 2011 a 2017 na pós-graduação em Direito da Propriedade Intelectual da PUC-RJ.

Desde março de 2012, Rafael é Professor Pesquisador da Faculdade de Ciências Econômicas (FCE) da Universidade do Estado do Rio de Janeiro (UERJ). Desde 2017 é membro permanente do corpo docente do Programa de Pós-Graduação em Ciências Econômicas (PPGCE), da mesma UERJ, onde leciona matérias na área de Economia do Setor Público e Microeconomia Aplicada (Regulação e Política Industrial).

Possui vasta experiência em pesquisa e docência em Análise Econômica do Direito, Direito da Concorrência, Propriedade Intelectual, Microeconomia Teórica e Aplicada e Teoria dos Jogos. Desenvolveu ainda 3 projetos de pesquisa junto ao Programa das Nações Unidas para o Desenvolvimento (PNUD), sendo o primeiro (2010-2011) precisamente sobre a interface entre 
Propriedade Intelectual e Defesa da Concorrência. O segundo (2012) versou sobre a utilização de instrumentos de propriedade intelectual para o desenvolvimento do setor de Defesa no Brasil. Ambos foram realizados junto à então Secretaria de Assuntos Estratégicos da Presidência da República (SAE/PR), ou seja, durante 3 anos Rafael foi consultor PNUD junto à Presidência da República.

A terceira consultoria especializada PNUD foi realizada em 2016 junto ao Conselho Administrativo de Defesa Econômica (CADE), i.e. o órgão antitruste brasileiro, para avaliação da utilização de remédios antitruste no Brasil e auxílio na confecção do Guia de Remédios Antitruste do órgão.

Em janeiro de 2019, Rafael tornou-se bolsista de extensão do CNPq com o projeto "Avaliação de impacto do uso de moedas sociais locais no Brasil", do qual é co-coordenador. Este projeto foi contemplado na Chamada CNPq No 36/2018 - C - Avaliação de Tecnologia Social.

Desde 01/10/2019, Rafael é Jovem Cientista do Nosso Estado pela Faperj. Seu projeto contemplado em edital homônimo versa sobre "Medicamentos: o embate entre Acesso e Inovação". Este projeto (e bolsa) tem vigência de 36 meses.

Desde 01/12/2019, Rafael integra o Grupo Emergente de Pesquisa em "Modelos de Teoria de Jogos, Contratos e Equilíbrio Geral aplicados: uma abordagem quantitativa", contemplado no Edital Faperj E_14/2019 - Apoio a Grupos Emergentes de Pesquisa no Estado do Rio de Janeiro 2019. Desta vez sua pesquisa contemplada é a centrada em Economia da Sustentabilidade.

O ano de 2019 foi, portanto, um divisor de águas na vida e carreira do Rafael. E se encerra com o lançamento do site www.propriedadeintelectualeconcorrencia.com.br e de uma série de livros em três volumes consagrada ao tema. Para completar, decide associar o lançamento dos livros ao financiamento de bolsas para os alunos mais carentes da FCE-UERJ.

Que venha 2020! 


\section{Índice}

I - Introdução

II - O Direito da Concorrência e a Propriedade Intelectual

III - As práticas anticoncorrenciais em Propriedade Intelectual

III.1 - Primeiras aproximações: EUA X Europa

III.1.1 - A Doutrina dos 9 No-No's

III.1.2 - O Entendimento Europeu

III.1.3 - O Guidelines americano de 1995 e o livro azul de 2007

III.2 - Cláusulas Especiais nos Acordos

III.2.1 - Cláusulas Especiais no Guidelines Americano de 1995

III.2.2 - O Entendimento Europeu

III.3 - Os casos Xerox

IV - As Condutas em Espécie

IV.1 - Recusa de Contratar envolvendo PI

IV.2 - Venda Casada em PI

IV.3 - Joint Venture de Pesquisa

IV.3.1 - Open Source

IV.4 - Licenciamentos Cruzados e Pool de Patentes

IV.5 - Estabelecimento de Padrões

V - Litigância Anticompetitiva

V.1 - O Direito de Petição e a Litigância de Má-fé

V.2 - A Litigância Anticompetitiva

V.3 - A Doutrina Noerr-Pendington

V.4 - O Pharmaceutical Sector Inquiry (PSI)

V.4.1 - O pré-PSI

V.4.2 - O Pharmaceutical Sector Inquiry (PSI)

V.4.3 - O caso Astra Zeneca

V.4.4 - O pós Astra Zeneca

Rafael Pinho de Morais, PhD.

www.rafaelpinhodemorais.com.br 
VI - A investigação de condutas em PI no Brasil

VII - Os atos de concentração e a Propriedade Intelectual

VII.1 - Condutas anticompetitivas e Atos de concentração

VII.2 - A Evolução no escrutínio de Atos de Concentração em setores de PI

VII.3 - Evidência de Atos de Concentração envolvendo PI no Brasil

VII.4 - Atos de concentração em seqüência no Brasil

VIII - As práticas anticompetitivas relacionadas à Propriedade Intelectual no Brasil

VIII.1 Recusa de contratar

VIII.2 Litigância anticompetitiva

VIII.2.1 A Experiência Norte-Americana

VIII.2.2 O Esforço Europeu

VIII.2.3 A litigância predatória (sham) no Brasil

IX - Aspectos teóricos da litigância predatória

IX.1 A litigância de má-fé e a litigância predatória

IX.2 Um novo critério para a litigância predatória

IX.3 Regulação farmacêutica e litigância predatória

IX.3.1 A Experiência Internacional

IX.3.2 A Experiência Brasileira

$\mathrm{X}$ - Análise de alguns setores específicos

X.1 O Setor Farmacêutico

X.1.1 Os cinco casos farmacêuticos atuais

X.1.2 O Inquérito sobre o Setor Farmacêutico (PSI) - versão brasileira

X.1.3 A Ressalva quanto a Atos de Concentração

X.2 O Setor de Cultivares

X.3 O Setor de Informática

X.4 O Setor de Autopeças

XI - As Possibilidades Jurídicas 
XI.1 O Arcabouço Jurídico Internacional

XI.1.1 A Declaração de Doha sobre o Acordo TRIPs e Saúde Pública

XI.1.2 Retaliação Cruzada na OMC

XI.2 O Arcabouço Jurídico Nacional

XI.2.1 Propriedade Industrial

XI.2.2 Defesa da Concorrência

XI.2.3 Cultivares

XII - Possibilidades concretas de atuação

XII.1 Direito Processual

XII.2 Falhas Regulatórias

XII.3 Evolução do entendimento

XII.4 Integração entre órgãos públicos

XIII - Propriedade Intelectual e Defesa da Concorrência

XIII.1 Práticas em Espécie

XIII.2 Atos de Concentração

XIV - Fundamentos da Intervenção Antitruste na Utilização da Propriedade Intelectual XIV.1 Uso Justo e Custos de Transação

XIV.2 Facilidades Essenciais

XIV.3 Finalidade da Norma

XV - Novas Tendências no SBDC em PI e Concorrência

XV.1 Dissociação entre questões de PI e outras questões

XV.1.1 A gestão coletiva de direitos autorais e o caso ECAD

XV.2 Incorporação do Direito do Consumidor ao Direito da Concorrência

XV.3 Análise efetiva de questões antitruste envolvendo PI

XV.3.1 Principais virtudes do caso Anfape

XV.3.2 Sham litigation em PI e o caso "Shop Tour"

XV.4 O não-conhecimento de licenciamentos de patentes

XV.4.1 Notificação de acordos de licenciamento de PI

XV.4.2 A experiência do SBDC em contratos de licenciamento 
XV.4.3 Os perigos do não-conhecimento

XV.4.4 Standards de prova e o não-conhecimento

XVI - Medidas concretas propostas

XVI.1 Integração entre os órgãos públicos

XVI.1.1 Utilização de procedimentos de busca e apreensão

XVI.1.2 Notificação de acordos judiciais e extra-judiciais

XVI.2 Alterações legislativas

XVI.2.1 Softwares e Direitos Autorais

XVI.2.2 Cultivares

XVI.2.3 A PI e o PL do Novo CADE (PL 3.937/2004)

XVI.2.4 Linhas gerais para um guia de análise

XVII - O Licenciamento Compulsório

XVII.1 Países Desenvolvidos

XVII.2 Países em Desenvolvimento e Países Subdesenvolvidos

XVII.3 As interações da Licença Compulsória

XVII.4 Experiência internacional em Antitruste

XVII.4.1 África do Sul

XVII.4.2 França

XVII.4.3 Itália

XVIII - Perspectivas para o Brasil

Bibliografia

Apêndice 1: Resultados das entrevistas com membros da Unidade Farma da Diretoria Geral de Concorrência (DGComp) da União Europeia

Apêndice 2: Resultados das entrevistas com membros da Office of Fair Trade britânico 


\section{I - Introdução}

A presente série consolida e atualiza os resultados da consultoria contratada no âmbito do Edital PNUD 020/2010, que buscou auxiliar a Secretaria de Assuntos Estratégicos da Presidência da República (SAE/PR) na adoção de políticas públicas pelo Governo brasileiro na interseção entre Defesa da Concorrência e Propriedade Intelectual (PI).

A importância do presente estudo não somente para o estado de coisas (constitucionalmente) desejável de Concorrência no ambiente econômico nacional é inegável. Auxilia ainda para a manutenção de incentivos à inovação e, por conseguinte, a existência de um fluxo tal de inovação capaz de promover o crescimento sustentável do Brasil. Nosso foco neste projeto é contribuir para este fim através da atuação do Sistema Brasileiro de Defesa da Concorrência (SBDC) ${ }^{1}$ no combate a práticas anticompetitivas relacionadas à obtenção e utilização da propriedade intelectual e no controle de atos de concentração onde propriedade intelectual seja tema crucial.

Este primeiro volume desta série cobre toda a parte teórica desta interface, sua evolução histórica e seu entendimento atual. É o volume mais robusto, mais longo e de mais conteúdo. O volume 2 cobre a jurisprudência antitruste nacional e internacional para o período 1890-2011. Já o volume 3 contempla a jurisprudência antitruste nacional para o período 2011-2018 e a internacional para o período 2011-2019.

Este volume 1 é a aglutinação dos 3 relatórios centrais (ou "Produtos") da consultoria PNUD junto à SAE/PR em 2010-2011. Por conta disso, alguns trechos podem soar como repetitivos - e o são. Na revisão final buscamos minimizar estas repetições e atualizar alguns pontos também. No entanto, optou-se por não eliminar itens já superados, até por sua importância histórica e para colaborarem para evitarmos erros parecidos no futuro. O maior exemplo disso é o não conhecimento de contratos de licenciamento, praticado pelo CADE durante mais de um ano, e abordado neste volume em sessão própria. Essa questão já foi revertida e encontra-se hoje superada no CADE - mas não o era em 2010-2011. Retirar deste volume os itens que tratam do não-conhecimento seria fingir que o problema não existiu, por isso a decisão de manter este e outros temas.

\footnotetext{
${ }^{1}$ O Sistema Brasileiro de Defesa da Concorrência (SBDC) engloba hoje no Brasil, sob a égide da Lei 12529/2012 (que sucedeu a Lei 8884/94), o Conselho Administrativo de Defesa Econômica (CADE), com seu Tribunal administrativo colegiado e sua Superintendência, atualmente (final de 2019) o órgão investigativo antitruste brasileiro. À época da consultoria PNUD para a SAE/PR que originou este volume, o SBDC era composto ainda pelo CADE (que continha apenas o Tribunal administrativo), pela Secretaria de Direito Econômico (SDE), órgão do Ministério da Justiça, e pela Secretaria de Acompanhamento Econômico (SEAE), órgão do Ministério da Fazenda. Existia à época o projeto de lei 5877/2005 - originalmente PL 3937/2004 - que se tornou projeto de lei da Câmara (PLC) 06/2009, que visava reestruturar o SBDC. Encontrava-se (em 13/01/2011 e desde 05/01/2011) na Comissão Especial da Câmara dos Deputados, para que esta emitisse parecer relativo às emendas aprovadas no Senado. Após o término de sua tramitação, foi aprovado em maio de 2011, entrando em vigor plenamente em maio de 2012 como Lei 12529/2012.
} 
Este primeiro volume desta série traz portanto um "relatório sobre as formas de utilização de instrumentos de propriedade intelectual de forma a impedir a concorrência”. Mais especificamente, destina-se a "identificar quais são e como funcionam as práticas anticoncorrenciais utilizadas para impedir de forma abusiva a livre concorrência, mais utilizadas no Brasil, na União Europeia e nos Estados Unidos e seus impactos sobre as empresas brasileiras". Os trechos entre aspas eram precisamente o descritivo do Produto 2 daquela consultoria PNUD junto à SAE/PR.

Ainda neste primeiro volume, esmiuçaremos os casos brasileiros de litigância anticompetitiva - foco maior do SBDC à época (2010/2011) na interface PI e Concorrência - para enfim apresentar as "possibilidades jurídicas permitidas pelo direito internacional e pelo direito nacional para combater abusos à concorrência com instrumentos de propriedade intelectual" (trecho do descritivo do Produto 3 da consultoria SAEPR). Medidas concretas serão também aqui estudadas.

Este primeiro volume por fim abordará as mudanças trazidas pelo então PL 3937/2004 (o PL do Novo CADE, que viria a se tornar a atual Lei 12529/2012) no tocante à interface PI e Concorrência e o que se poderia aprimorar em termos legislativos - sempre enfatizando que a legislação substantiva à época já era bastante adequada (com a exceção da proteção a softwares), mas que pouco havia sido feito nesta interface efetivamente, apesar de notáveis avanços à época. É de se registrar que a situação permanece em 2019: a legislação brasileira vigente (e que é estudada neste volume, quando ainda era projeto de lei) é adequada, mas a prática nos casos concretos não acompanha esta qualidade.

As possibilidades e dificuldades na aplicação do Direito da Concorrência a questões envolvendo Propriedade Intelectual são objeto de análise neste volume 1 desta séria. O volume 2 se destina especificamente a apresentar de forma sistematizada toda a jurisprudência apresentada ao longo do volume 1, com suas referências exatas e informações mais pertinentes.

O volume 2 sistematizará, portanto, o conhecimento adquirido durante as demais etapas de execução do projeto de pesquisa originalmente desenvolvido em 2010/2011 para a SAE/PR (e continuado com a IC Faperj de 2017/2019, objeto do volume 3) com relação aos casos nacionais e internacionais. Almejará criar um material de referência para advogados, o Ministério Público, Poder Judiciário, órgãos do SBDC (hoje CADE e SEAE), INPI e demais gestores públicos que lidam com o tema da interface entre Propriedade Intelectual e Defesa da Concorrência.

Por ora cabe a este volume 1 cobrir a teoria. 


\section{II - O Direito da Concorrência e a Propriedade Intelectual}

E por aí vai...

Para maiores informações, favor acessar www.pi-e-concorrencia.com.br 